13 Miklowitz DJ, Otto MW, Frank E, Reilly-Harrington NA, Kogan JN, Sachs $\mathrm{GS}$, et al. Intensive psychosocial intervention enhances functioning in patients with bipolar depression: results from a 9-month randomized controlled trial. Am J Psychiatry 2007; 164: 1340-7.

Steven H. Jones, Professor of Clinical Psychology, Spectrum Centre for Mental Research, Lancaster University, UK, email: s.jones7@lancaster.ac.uk; Fiona Lobban, Anne Cooke, Warren Mansell, Kim Wright and Joanne Hemmingfield, Spectrum Centre for Mental Research, Lancaster University doi: 10.1192/pb.35.11.432b

\section{The private sector v. the NHS: who's the good, the bad and the ugly?}

For psychiatrists who care for National Health Service (NHS) patients in the private and voluntary sectors, it can sometimes be dispiriting when colleagues make inclusive overtures, but manage at the same time to vent their spleen about the independent sector. Alistair Stewart, in the September lead correspondence item in The Psychiatrist, ${ }^{1}$ admits that there is 'the good, the bad and the ugly' in all sectors, and even that there are 'flagship private sector providers', but only lists recent quality failures linked to the activities of private equity groups. He would want to eschew the term independent sector as a 'polite fiction', preferring frankness such as 'the private sector milking the money which most taxpayers think is going to the $\mathrm{NHS}^{\prime}$. Are independent charitable providers and all wellmeaning professionals outside the NHS to be tarred with the same brush?

Similarly, in response to an editorial I co-authored, ${ }^{2}$ another NHS psychiatric colleague ${ }^{3}$ gives an unbalanced view, focusing on fraud in US healthcare, the profit motive and sharp practice, contrasting this with the NHS, which is apparently an example of 'a system based on trust and common purpose'. Is the truth not that in-house NHS services across the country include both shining examples of excellence and dedication, and scandalous failures of care and management - just as much or as little as many other kinds of organisation?

It is important to see that all sectors have been caught up in the same economic cycle. In the boom years the for-profit, commercial sector brought major investment in modern hospitals and community homes, from which NHS mental health patients have greatly benefited. Many would otherwise be homeless or in prison. The ultimate source of this commercial investment is mostly the savings of ordinary people, funnelled through investment funds of various sorts. Of course this was boosted by irresponsible borrowing, leading now to an intense resource squeeze, to unacceptable quality failures, and to investors making substantial losses.

All this parallels huge government investment in health services in recent years, the consequent public debt, and now severe reductions in spending, especially in social care. Mental health patients are among the vulnerable people affected, as care providers, including many community mental health charities, struggle to survive. Charities have to learn lessons from and compete with state and commercial provision, despite being challenged by the downturn through little fault of their own.

I would encourage NHS colleagues to acknowledge good work done by psychiatrists and mental health workers in every sector, in the best interests of patients, and balance their critical comments with examples of poor clinical practice wherever they arise. It is painful to see the fallout of the international debt crisis roll through our society and affect the most vulnerable. The responsibility rests perhaps with key decision makers in international public and private finance, but let us not become so conflicted that we waste our energies blaming each other in the mental health world.

\section{Declaration of interest}

St Andrew's is the UK's largest provider of charity sector services to the NHS.

1 Stewart AG. The NHS, the private sector and the future. Psychiatrist 2011; 35: 354

2 Sugarman P, Kakabadse A. Governance, choice and the global market for mental health. Int Psychiatry 2011; 8: 53-4.

3 Bernadt $M$. The English market model is not fit for export. Int Psychiatry 2011; 8: 55-6.

Philip Sugarman CEO and Medical Director, St Andrew's Healthcare, Visiting Professor, School of Health, University of Northampton, Honorary Senior Lecturer, Institute of Psychiatry, King's College London, St Andrew's Healthcare, Billing Road, Northampton NN1 5DG, UK, email: psugarman@standrew.co.uk

doi: $10.1192 /$ pb.35.11.434

\section{A response to Professor Sugarman}

Professor Sugarman's response to my letter in the September issue helps to clarify a number of points.

First, to deal with sentimental matters. I am sure that all well-meaning professionals outside and inside the NHS have honourable motives and are committed to their patients. However, this is not the real issue. We do not live in the 'mental health world' but in a world where the future of the NHS is being threatened by large private sector organisations keen to promote and benefit from certain policy changes. These, in the guise of promoting 'choice', will enable them to take large bites out of the NHS and establish the profit motive as the dominant force in healthcare in the UK, just as it already is in the USA. These organisations have been frustrated for a long time by the fact that the existence of the NHS in Britain has restricted opportunities for them. Emails made public this summer, sent by David Worskett, head of the amusingly named NHS Partners Network (representing groups such as UnitedHealth, Care UK, BUPA, the General Healthcare Group and Ramsay Health (are UK), demonstrate the determination of these companies to establish their bridgehead into the NHS.

Professor Sugarman says that the NHS is 'apparently [my emphasis] an example of a system based on trust and common purpose'. He may well find that very large numbers of people working in the NHS and using it see it in exactly that way, for all its failings.

Professor Sugarman seems keen in his letter to distinguish 'independent charitable providers' from the 'for-profit, commercial sector'. However, in the article he wrote with Professor Andrew Kakabadse in International Psychiatry, he appears quite ready to argue on behalf of 'providers with international experience' and 'the power of globalisation of markets and information' to promote 'improved care through choice for patients'. ${ }^{2}$ Is this how the charitable sector sees itself?

There are signs that some leaders of the charitable sector are smoothing the way for private sector organisations. The 